\title{
Sutural Morphology of Pterion in Uttarakhand Region
}

\author{
Rubina Victor ${ }^{1}$, Suchit Kumar ${ }^{2}$, Sadakat Ali ${ }^{3}$, Shashi Munjal ${ }^{4}$ \\ ${ }^{1}$ Department of Anatomy, SGRRIMHS, Dehradun, Uttarakhand, India. ${ }^{2}$ Department of Anatomy, SGRRIMHS, Dehradun, \\ Uttarakhand, India. ${ }^{3}$ Department of Anatomy, SGRRIMHS, Dehradun, Uttarakhand, India. ${ }^{4}$ Department of Anatomy, \\ SGRRIMHS, Dehradun, Uttarakhand, India.
}

ABSTRACT

\section{BACKGROUND}

Pterion is a significant region marked by the junction of frontal bone, parietal bone, squama temporalis and the greater wing of sphenoid and forms the floor of temporal fossa. It is the craniometric point on the lateral side of the skull used by neurosurgeons due to its sutural and anatomical importance. We wanted to evaluate sutural morphology of Pterion in crania of Uttarakhand adults.

\section{METHODS}

This is an observation study conducted in Department of Anatomy, Sri Guru Ram Rai Institute of Medical and Health Science, Dehradun. Sample of 80 skulls were taken of unknown sex.

\section{RESULTS}

80 skulls of unknown sex were observed. Three types of pterion were noted, the sphenoparietal type, the frontotemporal type and the stellate type. Occurrence of the sphenoparietal type was $81.25 \%$ on the right side of the skull and $86.25 \%$ on the left, frontotemporal type was found in $13.75 \%$ on the right side and $10 \%$ on the left side and the stellate type was found to be $5 \%$ on the right and $3.75 \%$ on the left side of the skulls. The same type of pterion occurred on both the sides in the same individual in $71.25 \%$ of the cases. The sphenoparietal type occurred more bilaterally. Epipetric pteria was not found in any of the skulls examined.

\section{CONCLUSIONS}

Sutural morphology of pterion in Uttarakhand region is more or less same as in other regions and populations. The only difference is the lack of Epipetric type of pterion in this region. The data may be used for future reference, when planning for surgical approaches to the cranium through this craniometric point.

\section{KEY WORDS}

Pterion, Skull, Sutural Morphology
Corresponding Author:

Dr. Suchit Kumar,

SGRRIMHS, Patenagar,

Opp. Mahant Indiresh Hospital,

Dehradun-2480001, Uttarakhand, India.

E-mail: rubinavictor@gmail.com

DOI: $10.14260 / j e m d s / 2019 / 699$

Financial or Other Competing Interests: None.

How to Cite This Article:

Victor R, Kumar $S$, Ali $S$, et al. Sutural morphology of pterion in Uttarakhand region. J. Evolution Med. Dent. Sci. 2019;8(43):3225-3228, $10.14260 /$ jemds/2019/699

Submission 13-08-2019,

Peer Review 09-10-2019,

Acceptance 17-10-2019,

Published 28-10-2019. 


\section{BACKGROUND}

The Pterion receive its name from the Greek word pteron meaning "wing". Pterion is a significant region marked by junction of frontal bone, parietal bone, squama temporalis and the greater wing of sphenoid bone and forms the floor of temporal fossa. It is the craniometric point on the lateral side of skull which is used by neurosurgeons due to its sutural and anatomical importance. It is located $3-4 \mathrm{~cm}$ superior to the midpoint of the zygomatic arch. It is usually indicated by an $\mathrm{H}$ - shaped formation of sutures that unite the frontal, parietal, sphenoid (Greater wing), and temporal bones. Less commonly, the frontal and temporal bone articulate; sometimes all bones articulate at one point.(1) Knowledge and understanding of the type and location of pterion and its relations to surrounding bony landmarks is important, especially with respect to neurosurgery.

Pterion is an important guide for age and sex determination as well as archaeological and forensic estimation. It is also an important site to assess anterior branch of middle meningeal artery, Broca's area, sphenoid ridge and optic canal. Initially pterion was classified into three types by Broca.(2) Murphy has described four types of pterion- sphenoparietal type where the great wing of sphenoid articulates with parietal bone to form letter $\mathrm{H}$; frontotemporal type where the squamous part of temporal articulates with the fontal bone; stellate type where all bones articulate in form of letter $\mathrm{K}$ and epipetric type where all sutural bones is lodged between the four bones forming the pterion.(3) The asterion is the junction of the parietal, temporal and occipital bones. The asterion is a surgical landmark to the transverse sinus location which is of great importance in the surgical approaches to the posterior cranial fossa. ${ }^{(4)}$ In the present study eighty dry skulls were examined for sutural morphology of pterion in crania of Uttarakhand adults and compared with the studies done in other region. The data may be useful to neurologists, radiologists and anthropologists.

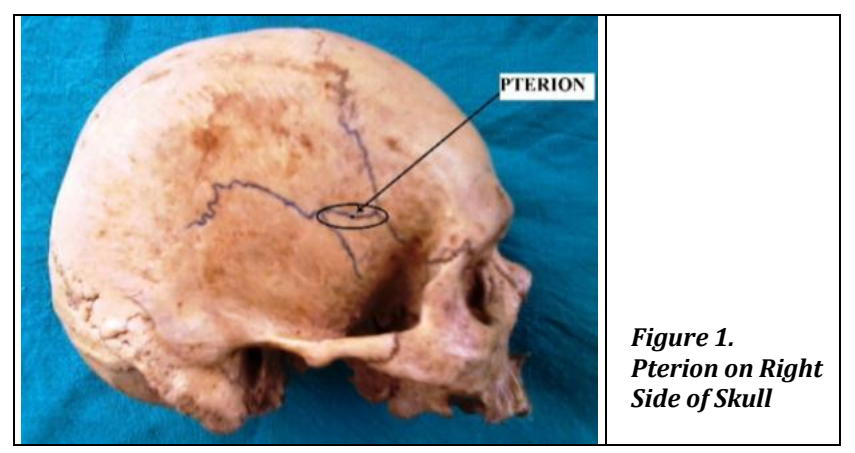

The pterion corresponds to the site of anterolateral fontanelle of neonatal skull which closes in the third month after birth. The joints of the cranial vault are sutural joints which ossify in membrane. As the bones are growing, the unossified sutural membranes connect the periosteum covering the outer and inner surface of the bone, which help in growth as well as binding the bones together as their opposed margin.(5) The most common variation is in shape and presence of epipteric bone.
Pterion is the region mostly used as a guide point where the position of deeper structures and their relations to the surface of the head are explained. This point is important landmark because the calvaria is thin in the region of pterion, which gets fractured easily at this point. It overlies anterior branch of the middle meningeal artery which is the most common artery to be damaged producing extradural haematoma, requiring burr hole surgery to evacuate haematoma.(6) Pterional approaches have paved the way for the management of wide variety of neurological disorders with minimal tissue injury, so proper knowledge of the pterion, its topography and morphology is mandatory for the pterional approach used in microsurgery. (7)

The Sylvian point, where the stem of lateral sulcus of cerebral hemisphere divides into its three limbs anterior, ascending and posterior, coincides with pterion. Pterion also overlies the broca's motor speech area (Area 44, 45) and insula of cerebrum.

The pterional approach is commonly employed in surgical treatment of the anterior circulation and upper basilar artery aneurysms, as well as for the tumours of orbit, retro-orbital, sellar, chiasmatic, subfrontal and prepontine areas, lesions around the sella and especially for the lesions behind the clivus. In the neurosurgery, it is important to have the most suitable bony aperture in order to be minimally invasive. To achieve precise craniotomy where neuro navigation devices are not available, the surgeon then relies on the external landmarks, such as pterion. The anatomic location of the pterion therefore is important in the surgical landmark by which the neurosurgeon can operate the patient of extradural haemorrhage as well as tumours involving inferior aspect of the frontal lobe. The other neurological conditions such as olfactory meningiomas can also be well take care through this approach. The 'pterional approach' may also be used in operations on the Broca's motor speech area and in repairing aneurysms of the middle cerebral artery as well as those of the upper basilar complex.(8)

\section{METHODS}

Present study is based on observation of 80 skulls of unknown sex. The study was conducted in department of Anatomy, Sri Guru Ram Rai Institute of Medical Health Sciences, Dehradun. Morphology of pterion on both the sides of each skull and the sutural pattern of the pterion were determined. The details of each skull were carefully noted and tabulated, the skull were marked from 1 to 80 .

\section{RESULTS}

Out of 80 skulls under observation only three types of pterion were reported; the sphenoparietal type, frontotemporal type and the stellate type. Epipteric type of pterion was not found in any of the skull. The sphenoparietal type was the predominating on both the sides- The sutural morphology of pterion was observed on each side of skull and tabulated. The sphenoparietal type was found on the right of 65 skulls, which accounts $81.25 \%$ on the right side and $86.25 \%$ on the left side of skulls. On both sides collectively it was $83.75 \%$, 
(Table 1). The fronto temporal type was found on the right side of 11 skull and on the left side of 8 skulls, which accounts $13.7 \%$ and $10 \%$ respectively. On the both sides collectively, it was found to be $11.87 \%$, (Table 1). The stellate type was found on the right side of 4 skulls and on the left side of 3 skulls which accounts $5 \%$ and $3.75 \%$ respectively. On the both sides collectively, it was found to be $4.38 \%$ (Table 1 ). None of the skull had epipteric type of pterion on either side.

\begin{tabular}{|c|c|c|c|}
\hline Type of Pterion & Right Side n= 80 & Left Side n= 80 & Both Sides n= 160 \\
\hline Sphenoparietal type & $81.25 \%$ & $86.25 \%$ & $83.75 \%$ \\
\hline Frontotemporal type & $13.75 \%$ & $10 \%$ & $11.87 \%$ \\
\hline Stellate type & $5 \%$ & $3.75 \%$ & $4.38 \%$ \\
\hline \multicolumn{3}{|c|}{ Table 1. Types of Pterion (Percent) } \\
\hline
\end{tabular}
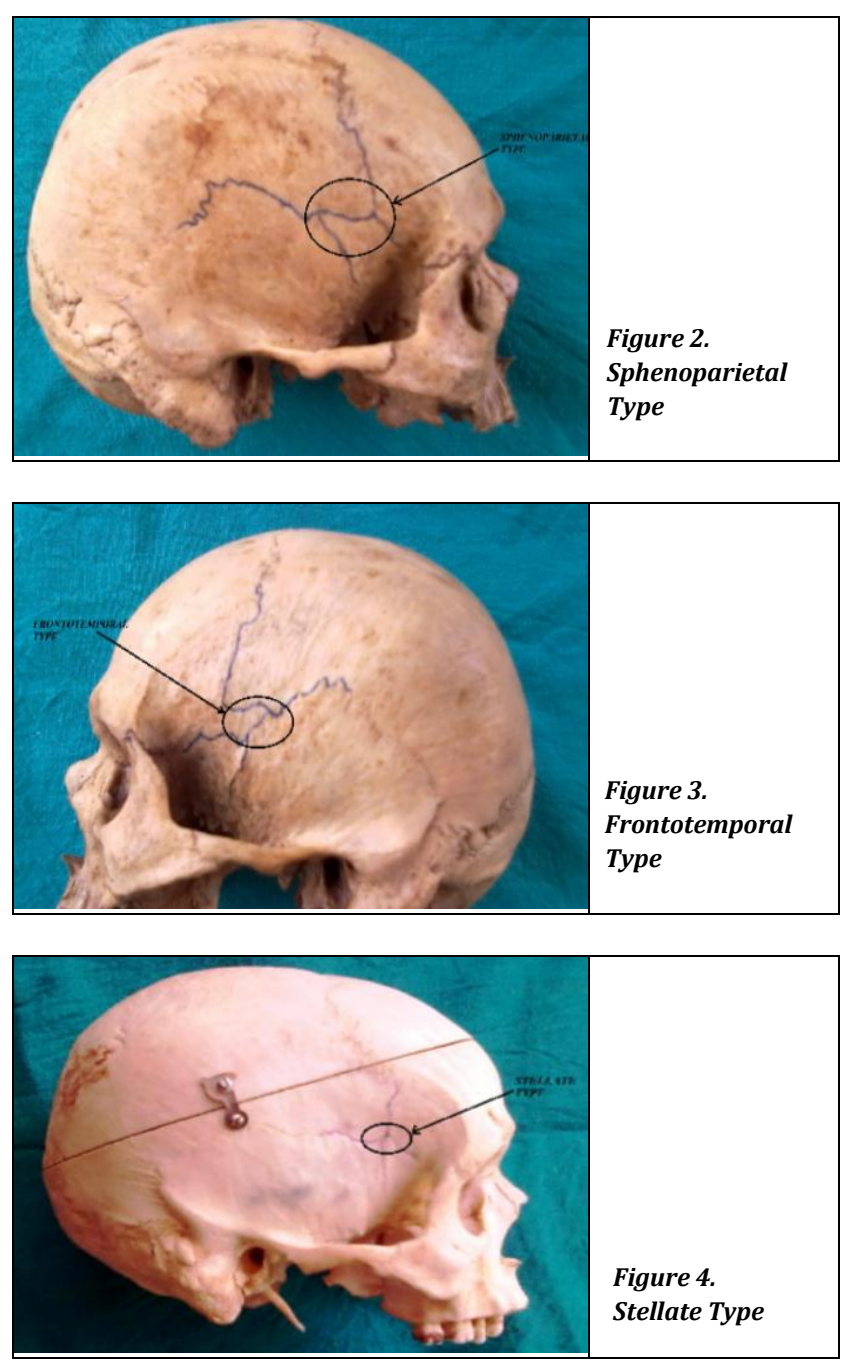

\section{DISCUSSION}

The present study has shown the same type of pterion occurs more bilaterally than unilaterally, this is in agreement with the findings among the Indians. ${ }^{(9)}$ The type and location of the pterion and its relation to surrounding bony landmarks is important. Such detailed information can only readily be obtained from an examination of dry skulls. However, as imaging techniques continue to develop, it may become possible to use these to determine more precise relationships between bony landmarks and the underlying soft tissues.(10) Sphenoparietal variety was predominant in the human skulls from sources in Gujarat and Awadh area around Lucknow. The present study also showed the same, sphenoparietal variety accounted $81.25 \%$ on the right and $86.35 \%$ in the left of the skulls of Uttarakhand region. This is relatively lower than the study done in Gujarat and in the region of Awadh area around Lucknow.

The symmetrical pairing of the pterion was not observed with all types, stellate variety did not show any symmetrical pattern. This variety was least present in the skulls of Uttarakhand region, where occurrence was nearly $4.38 \%$ (Both sides). In the study done in Gujarat(11) it is extremely low $0.02 \%$ but in the other study done in the region of Awadh area around Lucknow it accounts to $5.17 \%\left({ }^{(9)}\right.$ which is higher than the present study. Therefore the occurrence of stellate variety of pterion increases as we move from Gujarat to Uttar Pradesh The supraorbital keyhole approach is most frequently used for anterior circulation aneurysms and for the treatment of lesions within the anterior cranial base, but this approach has some drawbacks, including cosmetically poor appearance of the scar, forehead deformity, and difficulty in dealing with some types of middle cerebral artery (MCA) and internal carotid artery (ICA) aneurysms which has led surgeons to develop an alternative approach to the anterior cranial fossa through pterion. Thus, pterional approach was considered as the minimally invasive neurosurgical approach ideal for anterior and middle cranial fossa lesions.(12) These differences could be due to different sample sizes used in the study. The distances between the pterion and the lesser wing of the sphenoid and optic canal are of practical importance in surgical approaches to these regions via the pterion.(10) The knowledge on various pterional sutural types and the location of the pterion in relation to bony anatomical land marks are important while performing micro surgeries or mini craniotomy to approach anterior or middle cranial fossa through pterional approach.

Pterion is the weakest point of the human skull present in the temporal fossa which is formed by the four bones i.e. parietal, frontal, greater wing of sphenoid and temporal bones. This is most common site for fracture due to presence of thin bones. There are chances of collection of fluid or blood which can cause the compression to the brain substance which can result in the death of the patient. So, the burr hole is done to release the compression on the brain substance. The knowledge of various types of pteria are important, especially epipteric type which can be mistaken for fractured bones. In the present study the results of all types of the pteria are almost matching with other studies but the presence of epipteric type of pterion is more as compared to other studies.(13) It shows that epipteric type of pteria are more common in Indian population. The measurements for location of pterion in the temporal fossa will help in the surface marking of pterion. The present study will be helpful to the anatomists, neurosurgeons, anthropologist, forensic medicine and forensic dentistry in their diagnosis and treatment. $(13)$ 


\section{CONCLUSIONS}

The results of this study show sutural morphology of pterion in Uttarakhand region, is not much different when compared to that of other populations. Most abundant of all types was sphenoparietal type that is $83.75 \%$ in total cases. The occurrence of frontotemporal type accounted for $11.87 \%$ which is in accordance with the studies done in India or abroad. Lastly the stellate type accounted for $4.38 \%$ of the total cases, which also is similar to most of the studies. Epipteric type was not observed in any of the skulls of Uttarakhand region. Sutural morphology of pterion in Uttarakhand region is more or less same as in other regions and populations. The only difference is the lack of Epipteric type of pterion in this region. The data may be used for planning surgeries to the cranium. Recent advances in the use of minimally invasive technique and instrumentation permit certain intracranial aneurysms to be treated using very small openings known as "Key Hole" openings. Potential advantages of these approaches include reduced operative morbidity, fast patient recovery, and cost effectiveness in case management. Pterion is a keyhole approach to such kind of intracranial surgeries.(14) The main advantage of pterional approach is the gaining of a large space for the compressed intra-orbital contents to expand, including the decompression of the apex of the orbit and the superior orbital fissure so the narrowest part of orbit is relieved. Venous outflow may also be improved by the procedure, thus further decreasing the volume load.(15)

\section{ACKNOWLEDGEMENT}

We would like to thank the Department of Anatomy, Sri Guru Ram Rai Institute of Medical and Health Sciences, Patel Nagar, Dehradun, for providing us with dry human skulls and instruments for smooth conduction of our study. We would also like to thank our departmental clerk for her help in arranging the article content and attendants of the department for their co-operation during article work.

\section{REFERENCES}

[1] Moore KL, Dalley AF. Clinically oriented anatomy. $4^{\text {th }}$ edn. Baltimore: Lippincott Williams \& Wilkins 1999;83640.

[2] Broca P. Instructions craniologiques et craniométriques. Mém Soc Anthrop Paris 1875;2:1-203.

[3] Ilknur A, Mustafa KI, Sinan B. A comparative study of variation of the pterion of human skulls from $13^{\text {th }}$ and $20^{\text {th }}$ century Anatolia. Int J Morphol 2009;27(4):1291-8.

[4] Martinez F, Laxaque A, Vida L, et al. Topographic anatomy of the asterion. Neurocirugia (astur) 2005;16(5):441-6.

[5] Natekar PE, DeSouza FM, Natekar SP. Pterion: An anatomical variation and surgical landmark. Indian J Otol 2011;17:83-5.

[6] Snell RS. Clinical anatomy by regions. $8^{\text {th }}$ edn. Lippincott Williams and Wilkins 2008: p. 673, 686.

[7] Urzi F, Iannello A, Torrisi A, et al. Morphological variability of pterion in the human skull. Ital J Anat Embryol 2003;108(2):83-117.

[8] Bhargavi C, Saralaya V, Kishan K. Pterion: a site for neurosurgical approach. IJBR 2011;2(12):588-594.

[9] Saxena RC, Bilodi AKS, Mane SS, et al. Study of pterion in skulls of awadh area-in around Lucknow. KUMJ 2003;1(1):32-3.

[10] Havaldar PP, Shruthi BN, Saheb SH, et al. Morphological study on shapes of pterion. IJAR 2015;3(4):1555-8.

[11] Zalawadia A, Vadgama J, Ruparelia S, et al. morphometric study of pterion in dry skull of Gujarat region. NJIRM 2010;1(4):25-9.

[12] Cheng WY, Lee HT, Sun MH, et al. A pterion keyhole approach for the treatment of anterior circulation aneurysms. Minim Invasive Neurosurg 2006;49(5):25762.

[13] Gindha GS, Mir NS, Agarwal R. Morphometric study of pterion in dry human skull bone in north Indian population. Human Biology Review 2017;6(1):1-9.

[14] Feng WF, Qi ST, Huang SP, et al. Surgical treatment of anterior circulation aneurysm via pterion keyhole approach. Di Yi Jun Yi Da Xue Xue Bao 2005;25(12):1546-8.

[15] Ammirati M, Bernardo A. Anatomical study of the superior orbital fissure as seen during a pterional approach. J Neurosurg 2007;106(1):151-6. 